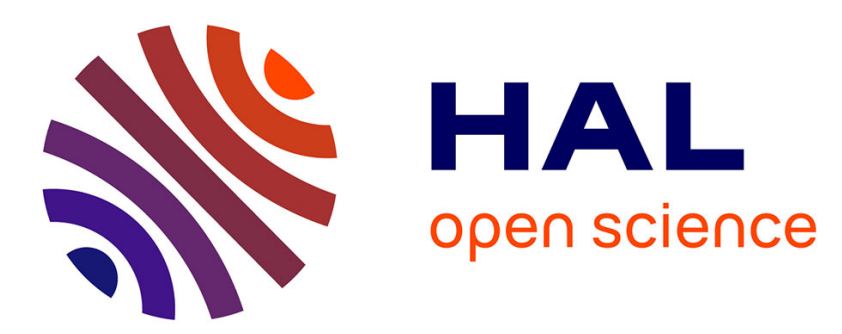

\title{
Diet and habitat selection in Cantabrian Capercaillie (): ecological differentiation of a rear-edge population
}

\author{
Beatriz Blanco-Fontao, Alberto Fernández-Gil, José Ramón Obeso, Mario \\ Quevedo
}

\section{- To cite this version:}

Beatriz Blanco-Fontao, Alberto Fernández-Gil, José Ramón Obeso, Mario Quevedo. Diet and habitat selection in Cantabrian Capercaillie (): ecological differentiation of a rear-edge population. Journal für Ornithologie = Journal of Ornithology, 2009, 151 (2), pp.269-277. 10.1007/s10336-009-0452-9 . hal-00568350

\section{HAL Id: hal-00568350 \\ https://hal.science/hal-00568350}

Submitted on 23 Feb 2011

HAL is a multi-disciplinary open access archive for the deposit and dissemination of scientific research documents, whether they are published or not. The documents may come from teaching and research institutions in France or abroad, or from public or private research centers.
L'archive ouverte pluridisciplinaire HAL, est destinée au dépôt et à la diffusion de documents scientifiques de niveau recherche, publiés ou non, émanant des établissements d'enseignement et de recherche français ou étrangers, des laboratoires publics ou privés. 
Diet and habitat selection in Cantabrian Capercaillie (Tetrao urogallus cantabricus): ecological differentiation of a rear-edge population

Beatriz Blanco-Fontao $^{1 *}$, Alberto Fernández-Gil ${ }^{2}$, José Ramón Obeso $^{1}$, Mario Quevedo $^{1}$

${ }^{1}$ Instituto Cantábrico de Biodiversidad (CSIC-UO-PA), Dpt. Biology of Organisms and Systems, Oviedo University. Campus del Cristo, 33006 Oviedo, Spain.

${ }^{2}$ Department of Conservation Biology, Estación Biológica de Doñana (CSIC). Avenida de Maria Luisa s/n, Pabellón del Perú, 41013 Seville, Spain

*Corresponding author. Email: bbfontao.uo@uniovi.es

Phone: +34985104830

Fax: +349851047 77 


\begin{abstract}
Cantabrian capercaillie Tetrao urogallus cantabricus is a peripheral population with distinctive phenotypic, biogeographic and genetic characteristics. Hence, the population may also show substantial ecological differentiation associated with its habitat in purely deciduous forests. We assessed seasonal diet selection, small scale habitat selection, and patterns of trophic niche width in Cantabrian capercaillie over two years. Diet was found to be a driver of small-scale habitat selection, a result consistent with previous studies of stand-scale habitat selection. Diet and habitat selection showed the importance of beech Fagus sylvatica, holly Ilex aquifolium, bilberry Vaccinium myrtillus and ferns in Cantabrian capercaillie's resource selection. Conversely, the abundant oaks Quercus petraea, birches Betula pubescens and heaths Erica sp. were used below their availability. The reliance on bilberry appears as a unifying characteristic between central and peripheral capercaillie populations. Cantabrian capercaillie showed stronger reliance on understory resources than range-central populations. It also showed wider trophic niche and higher specialization of feeding events. Trophic niche patterns and reliance on ground resources indicated a marked ecological differentiation, which stresses the need of local data and specific conservation actions.
\end{abstract}

KEY WORDS: rear-edge populations, ecological differentiation, diet selection, trophic niche, deciduous forests, Tetrao urogallus cantabricus 


\section{INTRODUCTION}

The ecological niche of a species (sensu Hutchinson 1957) can be quite variable across distribution ranges, leading to different realized niches and variability in the demographic and behavioral characteristics of local populations (e.g. Chase and Leibold 2003). Peripheral populations, closer to the limits of tolerance of a species, are embedded in a set of community interactions that differs, both in quality and strength, from that at the central parts of their species range (Gaston 2003). In this regard, conservation measures based on information from the central part of a species' range may be of limited use, or even counterproductive, at the edges of the range (Hampe and Petit 2005).

Not only can the realized niche of a species vary among populations across geographic ranges, but also intrapopulation variability in features such as diet and habitat selection is another potentially important source of variation (Smith and Skulanson 1996; Bolnick et al. 2003). Conservation plans that protect an average population trait (for instance, a folivorous bird species said to obtain $60 \%$ of its diet from trees) might fail when a population is built up of substantially different sex, ageclass or individual components (Durell 2000; Bolnick et al. 2003). That said, both the conservation consequences of variation within populations and the ecological characteristics of populations at the rear edge of distribution have been understudied (Durell 2000; Bolnick et al. 2003; Hampe and Petit 2005).

Capercaillie, Tetrao urogallus (Tetraonidae), in the Cantabrian Mountains of NW Spain is an endemic, rear edge population comprising the southwestern edge of the species' range (Castroviejo 1975), which in itself occupies a particularly southerly location within Palearctic grouse distribution (Storch 2007). Cantabrian capercaillie Tetrao urogallus cantabricus lives in purely deciduous forest in contrast to the vast 
majority of capercaillie populations that inhabit coniferous forests (Storch 2007). Hence, the population may be expected to show marked ecological and behavioral differentiation related to its distinct habitat. Although the population is known to be an Evolutionary Significant Unit and may be part of a distinct southern capercaillie lineage (Duriez et al. 2007; Rodríguez-Muñoz et al. 2007), its potential ecological peculiarities remain largely unknown (e.g. Storch 2007). Unfortunately, the population has been declining sharply at least in the last three decades, and hence is also unique in terms of conservation status (Storch et al. 2006).

The trophic ecology of a population may provide an appropriate evaluation of divergence from central ecological and behavioral trends because resource selection is a key aspect of the ability of animals to cope with their environment. This is especially true in the case of herbivorous birds, which need to devote a lot of time to foraging, due to their low intake rate and relatively small guts (Sedinger 1997; van Gils et al. 2007). Grouse specialize on different food resources depending on local conditions, although usually only a few plant species are important throughout the entire range (Sedinger 1997). Capercaillie are mostly folivores, however, diet and habitat selection probably vary substantially from the well-known habitat in boreal forest to the purely deciduous Atlantic montane forests. Bilberry may be a major exception to such differentiation (Storch 1993; Quevedo et al. 2006b). Hence, diet selection could be an important mechanism to explain patterns of habitat selection in birds like capercaillie at the scale of individual daily ranges.

In another biogeographic peculiarity, capercaillie is the only extant grouse species in the Cantabrian Mountains; hence it does not compete for resources with any closely related species. Furthermore, in winter and early spring, deciduous forests lack the permanent food and shelter supplied by the needles of coniferous forests which could be 
a key environmental constraint driving ecological differentiation. These peculiarities lead us to expect higher diversification in the diet of Cantabrian capercaillie and wider trophic niche than in conifer-dwelling populations. Previous studies have indeed shown that the diet of Cantabrian capercaillie might be varied (Castroviejo 1975; Martínez 1993; Rodríguez and Obeso 2000). However, these studies were based on opportunistic sampling schemes and did not address diet selection. Nonetheless, they have provided several hypotheses along the interface of diet and habitat selection for further investigation. For instance, the widely assumed importance of holly Ilex aquifolium for Cantabrian capercaillie (Castroviejo 1975), or the paradoxical minor importance in the diet of sessile oak Quercus petraea (Martínez 1993; Rodríguez and Obeso 2000), a canopy species that dominates large forest patches with capercaillie presence in the Cantabrian Mountains (Quevedo et al. 2006b).

In this study, we evaluated year-round diet selection, small-scale (daily-range) habitat selection and trophic niche width in an area of presumed good habitat quality for Cantabrian capercaillie (Quevedo et al. 2006a). We aimed specifically to assess the potential relationship between diet and small-scale habitat selection in the population, and to see how this related to previous stand-scale studies (Quevedo et al. 2006b). We also evaluated the extent of diet-related ecological differentiation of this peripheral population compared with other range-central capercaillie populations. 


\section{METHODS}

\section{Study area and survey design}

The fieldwork was conducted over a $10-\mathrm{km}^{2}$ tract of forested habitat on the northern slope of the western Cantabrian Mountains (NW Spain), centered at $42.94^{\circ} \mathrm{N}-6.48^{\circ} \mathrm{W}$, between August 2002 and April 2004. Altitude in the study area ranges from 900 to $1900 \mathrm{~m}$ a.s.1., and the average slope is $21 \%$, resulting in a rugged landscape. Siliceous soils are the substrate of a mixed forest mostly composed of mountain birch Betula pubescens (39\%), sessile oak Quercus petraea (30\%), and beech Fagus sylvatica (14\%). Isolated trees or small groups of holly Ilex aquifolium and rowan Sorbus aucuparia also occur scattered through the forest. The treeline lies at about $1600 \mathrm{~m}$ a.s.l., and is a fine-grained mixture of birch thicket, tree heaths Erica arborea, common heather Calluna vulgaris and bilberry Vaccinium myrtillus, broom formations (Genista florida, Cytisus scoparius), grazing meadows, and talus.

The study area held at least three display areas occupied in 2001. Previous observations by forest rangers and the authors showed that the area included also capercaillie brooding, moulting and wintering areas. The study area was also chosen because of its relatively stable occupancy of display grounds compared to the overall population (M. Quevedo unpubl. data), its overall habitat quality for capercaillie in a previous model (habitat suitability values >0.60, Quevedo et al. 2006a), and the negligible presence of domestic ungulates (cattle and horses).

Sampling units were 10 plots of $1 \mathrm{~km}^{2}$ each, based on the UTM grid, which covered the complete surface of the study area. All plots were surveyed bimonthly, from August 2002 to April 2004. The same observer surveyed all the plots, devoting a sampling effort of three hours per plot and zigzagging within its boundaries. Signs of capercaillie 
presence, such as direct sightings, fresh droppings, feathers, and footprints, were used to determine habitat use by recording vegetation composition and cover (to the nearest $5 \%$ ). These variables were visually estimated for both canopy and understory within a circle of $25 \mathrm{~m}$ radius $\left(2000 \mathrm{~m}^{2}\right)$ centered on the sign of capercaillie presence. The minimum distance to consider signs as independent samples was $50 \mathrm{~m}$. All signs were collected (droppings, feathers) or erased (footprints) in each survey to ensure that they were recorded only once. Droppings were stored for posterior diet analysis. Additionally, to collect identical information on resource and habitat availability, control spots were selected randomly by taking one every 30 minutes of survey in each of the 10 sampling plots.

\section{Diet analyses}

We used microhistological methods to identify plant remains in the droppings of capercaillie, which were then compared to a library of reference material. Although these methods may present some bias (reviewed in Holechek et al. 1982), they are nonintrusive thus allowing the study of diet in secretive and endangered populations (Holechek et al.1982). Moreover, fecal analysis has been widely and successfully applied in the study of diet selection in herbivorous birds (e.g Owen 1975; Madsen and Mortensen 1987). The technique relies on the resistance of plant epidermis to herbivore digestion, which leaves plant fragments undigested and identifiable in the droppings (Holechek 1982; Alipayo et al. 1992). The reference material was prepared from 28 potential food sources, determined from previous studies of capercaillie diet in the Cantabrian Mountains (Castroviejo 1975; Martínez 1993; Rodríguez \& Obeso 2000) and plant availability in the particular study area. To do this, samples were dried at $60^{\circ} \mathrm{C}$ for $48 \mathrm{~h}$, ground with a Retsch MM200 ball mill and rinsed with $\mathrm{NaOCl}$ to improve clarity (Holechek 1982). Samples were then centrifuged to eliminate the supernatant 
fluid, and subsequently rinsed and centrifuged twice with distilled water. The resultant material was sieved through 1 and $0.2 \mathrm{~mm}$ pore-size filters, and the intermediate fraction was kept for analysis. Approximately $30 \mathrm{mg}$ of the sieved material was mounted on a slide with a hydrophilic mounting medium (Jung Tissue Freezing Medium). These reference slides were studied carefully before proceeding with diet slides, and the specific features of the epidermis (cells shape, hairs and trichomes, stomas) were digitally photographed under a $100 \times$ microscope.

Previous tests had been carried out to determine the asymptote of the relationship between the diversity of plant remains and fragments counted. As a result the number of plant remains identified per sample was fixed at 50 along two transects, i.e. the first 25 non-overlapping fragments intercepted per transect/scale line under a $100 \mathrm{x}$ microscope. Samples were classified into spring (March-June), summer-autumn (July-October) and winter (November-February), based on capercaillie life cycle and plant phenology. Diet composition was used to calculate the proportion of understory resources in the diet and to compare it with other capercaillie populations.

\section{Diet and habitat selection}

Diet selection was analyzed based on 11 plant categories, split into canopy and understory. Canopy categories consisted of the main tree species in the study area: beech, sessile oak, birch, holly and rowan. Diet selection on understory plants was analyzed using the following categories: broom, bilberry leaves, berries and shoots, heaths, heather, ferns and grasses. These categories were chosen to represent, to some extent different, microhabitats, and maintain a balance between a too coarse-grained scheme that would underestimate selection, and a too fine-grained one that would merely reflect the natural patchiness of resources. 
Diet and habitat selection were determined using design I (population level) selection ratios (Manly et al. 2002). These ratios are proportional to the probability of each category being used, assuming unrestricted access to available resources. Selection ratios range from 0 (null selection) to infinite (maximum positive selection), where 1 indicates that resources are used according to availability. Vegetation composition and cover data, in both used and control spots, was pooled together, and the mean over the whole study area was used as an estimation of habitat and food availability (Shuterland and Green 2004) of perennial resources. In the case of ferns and grasses, availability was estimated on a seasonal basis.

\section{Niche width}

Total trophic niche width and specialization of feeding events were estimated following metrics that use the total diet of the population to define resource availability. These metrics have been reviewed and updated by Bolnick et al. (2002), providing companion software IndSpecl that facilitates metric calculations and provides resampling routines. To estimate total niche width $(T N W)$ we used an index adapted to discrete data (Bolnick et al. 2002):

$$
T N W=-\sum_{j} q_{j} \ln q_{j}
$$

where $q_{j}$ is the proportion of the $j^{\text {th }}$ food category in the population's niche. The degree of specialization in feeding events for the population was estimated by means of the mean proportional similarity index (IS, Bolnick et al. 2002):

$$
I S=\frac{\sum_{i}^{n} \sum_{j} \min \left(p_{i j}, q_{j}\right)}{n}
$$


where $p_{i j}$ is the proportion of the $j^{\text {th }}$ food category in each dropping or feeding event $i$, and $q_{j}$ are the same as above. Then, proportions of the different categories in the diet of the population are calculated as the average proportion of each food category. This similarity index estimates the degree of overlap between a given sample and the population. It approaches 0 for fully specialized feeding events (monodiet), and 1 for those with a generalist pattern. The main advantages of this metric over others available are that it estimates specialization for each sample, it is not too sensitive to artifacts due to the presence of purely monophagous samples, and it makes no assumption about particular distributions of resources (Bolnick et al. 2002). IndSpec1 provides a Monte Carlo routine to test the significance of the $I S$ index against a null model of a fully generalized diet. We compared overall, generalized and seasonal $I S$ values by means of one-way ANOVAs and post-hoc Tukey tests. All analyses were performed with freeware (R Development Core Team 2008).

Lastly, we calculated TNW (as described above) and the proportion of understory resource use for other published studies on capercaillie diet (Jacob 1988; Storch et al. 1991; Picozzi and Catt 1996; Saniga 1998; Summers et al. 2004). To allow for comparison with our population, we only considered the studies that (1) showed yearround quantitative data for adult animals and, (2) at least had the same taxonomic resolution as our data. Additionally, diet categories in these studies were grouped according to categories from our data, that is: all tree and shrub species appearing in the diet, animal material, ferns, grasses, mosses and unidentified plant remains. 


\section{RESULTS}

Sampling surveys over the two-year period yielded 146 signs of capercaillie presence in the $10 \mathrm{~km}^{2}$ study area. Most of these signs were droppings (122), although feathers, footprints, and direct sightings were also included in the analyses of habitat selection. Signs of presence were balanced across seasons (spring $=46$, summer-autumn $=57$, winter $=43$ ).

\section{Diet and habitat selection}

The 122 diet samples analyzed yielded only two monodiets, both consisting of holly leaves in winter and early spring. In spring, diet was dominated by beech buds, bilberry shoots and fern fronds, at $28 \%, 19 \%$ and $16 \%$, respectively $(\mathrm{n}=43)$. In summerautumn, major diet items were 54\% bilberry and $10 \%$ fern fronds $(n=49)$. Most bilberry consumption in this period consisted of berries $(63 \%)$. In winter $(n=30)$, holly leaves accounted for 33\% of the diet, and beech buds, bilberry shoots and fern fronds accounted for 13\% each. See Appendix 1 for details on proportional use and availability.

Diet selection index for tree species showed that beech and holly were preferred, whereas birch, oak and rowan were consumed below availability. Results in spring and winter mirrored the overall trend except for beech in winter, which was consumed according to its availability (Fig.1a). In summer-autumn, only rowan, which was not consumed at all, departed from availability (Fig.1a). Among understory species, bilberry and ferns were important in the diet selection. Bilberry was strongly selected in summer-autumn, whereas ferns were strongly selected in spring and winter (Fig.1a). Heaths and brooms, the former a particularly abundant resource, were always used below availability (Fig.1a). Cantabrian capercaillie obtained much higher percentages of 
understory or ground-based resources than other populations, averaging $65 \%$, with maximum in summer-autumn $(83 \%)$ and minimum in winter $(50 \%$, Table 1$)$.

Habitat selection for tree species did not show a clear pattern. In spring, beechdominated areas were used above availability whereas oak-dominated areas were used below availability. In summer-autumn, holly was used below availability (Fig.1b). Habitat selection for understory vegetation showed that areas rich in bilberry and grasses were preferred in winter and spring, whereas areas rich in ferns were used below availability in spring, and brooms or common heather were used below availability all year round (Fig.1b).

\section{Niche width and diet similarity index}

We found that TNW in Cantabrian capercaillie was wider than in any other capercaillie population analyzed (Table 1). Both overall and seasonal values of the similarity index $(I S)$ for our study population were significantly different from a generalized resource use (Table 2). In addition $I S$ varied between seasons $\left(\mathrm{F}_{2,119}=11.3\right.$, p $<0.0001$, Fig. 2) indicating that the specialization of feeding events was higher in winter than in spring and summer-autumn $(p=0.016$ and $p<0.001$ in Tukey HSD tests, respectively). 


\section{DISCUSSION}

\section{Ecological singularity}

In this study we confirmed that living in purely deciduous forests bears trophic and possibly behavioral consequences for capercaillie. Cantabrian birds obtained annually $65 \%$ of their resources on the ground, whereas other populations ranged between 14 and $43 \%$, averaging $34 \%$. This contrast appears particularly marked in winter, arguably the season with more pronounced structural differences between deciduous and conifer forests. The differences may be due to the lack of foliage in winter and early spring in deciduous forests, together with the rugged terrain where plants protrude above the snow in ridges, whereas the availability of conifer needles in most populations allows the birds to use trees as their primary food source. This result is a mechanistic example of differential interactions with both biotic and abiotic components of the environment, predicted for peripheral populations (e.g. Gaston 2003). Several consequences could result from this behavioral peculiarity. For instance, we speculate that higher reliance on understory resources may imply that Cantabrian birds are more susceptible than boreal birds to the overall unfavorable competition with large mammalian herbivores (van Gils et al. 2007).

In other capercaillie populations and forest grouse species, foraging is often concentrated on individual food-items, and includes perching in individual trees for days or even weeks (Bergerud and Gratson 1988; Sedinger 1997). We found almost no such monodiet feeding events. In addition, diet and habitat preference showed several contrasting results, especially for holly and ferns, which were preferred as winter diet but were not especially common as part of winter habitat. All in all, we interpret this as a markedly distinct foraging behavior in which Cantabrian capercaillie moved more 
often and farther while foraging, departing from the usual overlap between food and cover found in other capercaillie populations and forest grouse species (reviewed in Bergerud and Gratson 1988).

\section{Mechanisms of habitat selection}

The high proportion of understory resources in the diet of capercaillie may partially explain the results of previous, larger-scale studies, which showed that stand-scale forest composition was not a key factor for habitat selection in Cantabrian capercaillie (Quevedo et al. 2006b). In addition, previous studies of stand-scale habitat selection also suggested a preference for areas richer in bilberry (Quevedo et al. 2006b), a trend which our diet analyses confirmed. Bilberry appears in high proportion in the diet all year round, and the birds positively selected it in summer-autumn. Leaves, shoots and, mostly, berries were consumed. Therefore, bilberry reliance seems to be a general characteristic of both central and peripheral capercaillie populations (Martinez 1993; Storch 1993; Rodríguez and Obeso 2000, Selås 2000). It also appears that bilberry, a major source of food and shelter for adults and chicks (e.g. Storch 1994, Wegge et al. 2005), is the only major diet resource shared with birds from the conifer domain.

\section{Diet selection and trophic niche width}

The phenology of deciduous forests determines the availability of resources for herbivores. This may explain the highly positive selection of holly and ferns in winter and spring. Holly is the only evergreen tree species in the study area, although it appears highly scattered within the forest; it was present only in 82 of 429 surveyed plots, averaging 3\% availability. Hence, as suggested in previous studies (Castroviejo 1975, Martinez 1993, Rodríguez and Obeso 2000), holly is a key winter food resource for Cantabrian capercaillie that may also provide shelter. Also important in the winter diet 
were beech buds, the first to appear in the season in these forests (B. Blanco-Fontao, pers.obs.). Diet preferences shifted markedly in summer-autumn, when Cantabrian capercaillie converged with other populations and selected bilberry. Conversely, the abundant oak and birch (taken together, representing a total of $69 \%$ of the canopy) and heaths ( $29 \%$ of understory), were consumed below availability. In the case of oak and birch, the low consumption may be related to the phenology of beech and bilberry, because the former is the first tree species to produce buds in winter, and the latter provides widespread supply of fresh leaves before oak and birch unfold theirs. This idea is supported by the use of beech as both a diet and habitat resource beyond its availability (Fig. 1). Nonetheless, accurately explaining such diet shifts would require higher sampling frequency than in this study as well as chemical determinations. Overall, we found stronger patterns of diet and habitat selection in spring (Fig. 1), perhaps reflecting the fact that resources are still scarce in early spring, the season that marks the onset of the energy-demanding reproductive period for capercaillie.

We found that Cantabrian capercaillie showed a broader TNW than the other capercaillie populations studied. This result confirms our expectations based on both the strong seasonality of resource availability in deciduous forests, and the lack of interspecific competition with other grouse species that may lead to niche expansion (Van Valen 1965; MacArthur et al. 1972; Costa et al. 2008). Interestingly, TNW of Cantabrian capercaillie was closest to that of those capercaillie populations living in montane habitats, like the Jura Mountains and Bavarian Alps.

There were substantial seasonal differences in niche patterns. Niche width was narrower and the specialization of feeding events was lower in summer-autumn, as the population foraged on the preferred bilberry fruits. In winter we found the opposite: more food items were included in the diet, but single feeding events were less similar to 
the population overall. We interpret this as a consequence of the lack of an abundant, widespread resource for folivores in winter and early spring in deciduous forests, compensated for by a broader niche than other capercaillie populations. This result is also consistent with previous, larger scale results indicating a more varied winter habitat use in Cantabrian capercaillie (Quevedo et al. 2006b).

\section{Final remarks}

Our study showed substantial ecological differences between Cantabrian and rangecentral capercaillie populations, and strong reliance on bilberry as a common feature among them. Our results stress the need for specific, local data to develop sound conservation plans, and suggest that bilberry, an important ground resource for Cantabrian capercaillie, should be specifically protected in capercaillie recovery plans. Most extant capercaillie areas in the Cantabrian range are protected (e.g. Quevedo et al. 2006a), but such protection does not prevent overgrazing on bilberry and other resources. Free-ranging livestock, though extensive and considered 'traditional', attain densities up to an order of magnitude larger than those of wild ungulates in some areas. Moreover, they double the highest densities of native ungulates in protected areas where overgrazing has been long discussed, like the Northern Range of Yellowstone National Park (Rodríguez et al. 2007). Reducing the season and range over which cattle herds graze and trample freely within sensitive areas has already been suggested to protect the habitat of brown bears Ursus arctos in the Cantabrian range (Naves et al. 2006). We suggest that limiting overgrazing by livestock may also help capercaillie directly by reducing competition, and indirectly by improving bilberry productivity (Tolvanen 1994). 
In this study we did not attempt to discriminate between hen and cock droppings because the overlap between them may be sometimes substantial, adding too much uncertainty to our quantitative approach. We considered that visual discrimination of sex from capercaillie droppings may be hampered by individual diet variation and seasonal diet shifts, which may be particularly important in our fine-grained study area. Nonetheless, sexual dimorphism and individual variation are potential sources of variability that could affect the understanding of capercaillie ecology and management plans (e.g. Bañuelos et al. 2008). Intrapopulation variability in the use of resources should be addressed by specific studies that assign diet unequivocally to individuals, perhaps combining microhistological and molecular techniques.

\section{Zusammenfassung}

Ernährung und Habitatwahl des Kantabrischen Auerhuhn (Tetrao urogallus cantabricus): ökologische Unterscheidung einer randständigen Population

Das Kantabrischen Auerhuhn ist geographisch randständig verbreitet und hat phänotypisch, biogeographisch und genetisch eindeutige Merkmale. Deshalb sind substanzielle ökologische Unterschiede assoziiert mit dem Habitat, reinem Laubwald, relativ zu zentralen Auerhuhnpopulationen, zu erwarten. Wir haben die saisonale Nahrungswahl, die kleinräumige Habitatnutzung und die Verteilung der trophischen Nische des Kantabrischen Auerhuhns über zwei Jahre erfasst. Übereinstimmend mit vorherigen Studien war die Ernährung ein wichtiger Faktor bei der kleinräumigen Habitatwahl. Nahrungs- und Habitatwahl zeigte die Bedeutung von Buchen (Fagus sysvatica), Stechpalmen (Ilex aquifolium), Heidelbeeren (Vaccinium myrtillus) und Farnen für Ressourcenwahl Kantabrischer Auerhuhner auf. Umgekehrt wurden die reichlich vorhandenen Eichen (Quercus petraca), Birken (Betula pubescens) und Heidekraut (Erica sp.) weniger genutzt als ihre Verfügbarkeit es zulassen würde. Die Abhängigkeit von Heidelbeeren scheint ein gemeinsames Merkmal der zentralen und randständigen Populationen der Auerhühner zu sein. Kantabrische Auherhühner zeigten eine stärkere Abhängigkeit von Unterholzressourcen als Populationen im Zentrum des Verbreitungsgebietes. Sie zeigten ebenfalls eine größere Nischenbreite und einen höhere Spezialisierungsgrad von 
Nahrungsereignissen. Die Verteilung der trophischen Nische und die Abhängigkeit von Unterholzressourcen weisen auf eine ausgeprägte ökologische Differenzierung hin; dies betont die Erfordernis und den Belang lokaler Daten für spezifische Naturschutzmassnahmen.

\section{ACKNOWLEDGEMENTS}

We thank Mariajo Bañuelos for reviewing the manuscript and R. Lendrum for linguistic advice. Ricardo García González, Jorge Tolivia and Anil Shresta assisted us with the microhistological method. We also thank Adán Abajo for his help with the database. The study was funded by a PFPU-MEC fellowship to BBF and grants BOS2001-2391C02-02, from Spanish Education and Science Ministery (MEC), and CN-05-018, from the Asturian Environmental Agency to JRO. 


\section{LITERATURE CITED}

Alipayo D, Valdez R, Holechek J L, Cardenas, M (1992) Evaluation of microhistological analysis for determining ruminant diet botanical composition. J Range Manage 45:148-152

Bañuelos MJ, Quevedo M, Obeso JR (2008) Habitat partitioning in endangered Cantabrian capercaillie Tetrao urogallus cantabricus. J Ornithol 149:245-252

Bergerud, A T, Gratson, M W (1988) Adaptive Strategies and Population Ecology of Northern Grouse. University of Minnesota Press, Minneapolis

Bolnick D I, Svanbäck R, Fordyce J A, Yang L H, Davis J M, Hulsey C D, Forister M L (2003) The ecology of individuals: incidence and implications of individual specialization. Am Nat 161:1-28

Bolnick D I, Yang L H, Fordyce J A, Davis J M, Svanbäck R (2002) Measuring individual-level resource specialization. Ecology 83:2936-2941

Castroviejo J (1975) El urogallo en España. Monografías de la Estación Biológica de Doñana, CSIC

Chase J M, Leibold M A (2003) Ecological niches: linking classical and contemporary approaches. The University of Chicago Press, Chicago

Costa G C, Mesquita D O, Colli G R, Vitt L J (2008) Niche expansion and the niche variation hypothesis: Does the degree of individual variation increase in depauperate assemblages? Am Nat 172:868-877

Durell S (2000) Individual feeding specialization in shorebirds: population consequences and conservation implications. Biol Rev 75:503-518

Duriez O, Sachet J M, Ménoni E, Pidancier N, Miquel C, Taberlet P (2007) Phylogeography of the Capercaillie in Eurasia: what is the conservation status in the Pyrenees and Cantabrian Mounts? Conserv Genet 8:513-526

Gaston K J (2003) The structure and dynamics of geographic ranges. Oxford University Press, Oxford

Hampe A, Petit R J (2005) Conserving biodiversity under climate change: the rear edge matters. Ecol Letters 8:461-467

Holechek, J L (1982). Sample preparation techniques for micro-histological analysis. J Range Manage 35:267-268

Holechek J L, Vavra M, Pieper R D (1982) Botanical composition determination of range herbivore diets - a review. J Range Manage 35:309-315 
Hutchinson G E (1957) Population Studies - Animal Ecology and Demography Concluding Remarks. Cold Spring Harbor Symposia on Quantitative Biology $22: 415-427$

Jacob L (1988) Régime alimentaire du Grand Tétras (Tetrao urogallus) et de la Gélinotte des bois (Bonasa bonasia, L.) dans le Jura. Acta Oecol 9:347-370

MacArthur R H, Diamond J M, Karr J R (1972) Density compensation in island faunas. Ecology 53:330-342

Madsen J, Mortensen C E (1987) Habitat exploitation and interspecific competition of molting geese in East-Greenland. Ibis 129:25-44

Manly B , McDonald L, Thomas D, McDonald T, Erickson W (2002) Resource Selection by Animals: Statistical Design and Analysis for Field Studies, 2nd ed. Kluwer Academic Publishers, London

Martínez A M (1993) Contribución al conocimiento de la eco-etología del urogallo cantábrico. Ph.D.dissertation, University of León, León

Naves J, Fernandez-Gil A, Rodríguez C, Delibes M (2006) Brown bear food habits at the border of its range: A long-term study. J Mammal 87:899-908

Owen M (1975) An assessment of faecal analysis technique in waterfowl feeding studies. J Wildl Manage 39:271-279

Picozzi N, Catt D (1996) Capercaillie habitat, diet and management in a Sitka spruce plantation in central Scotland. Forestry 69(4):373-388

Quevedo M, Bañuelos M J, Obeso J R (2006a) The decline of Cantabrian Capercaillie: How much does habitat configuration matter? Biol Conserv 127:190-200

Quevedo M, Bañuelos M J, Sáez O, Obeso J R (2006b) Habitat selection by Cantabrian Capercaillie at the edge of the species distribution. Wildl Biol 12:267-276

R Development Core Team (2008) R: A language and environment for statistical computing. R Foundation for Statistical Computing, Vienna, Austria

Rodríguez-Muñoz R, Mirol P M, Segelbacher G, Fernández A, Tregenza T (2007) Genetic differentiation of an endangered Capercaillie (Tetrao urogallus) population at the Southern edge of the species range. Conserv Genet 8:659-670

Rodríguez A E, Obeso J R (2000) Diet of the Cantabrian Capercaillie: geographic variation and energetic content. Ardeola 47:77-83

Rodríguez C, Naves J, Fernández-Gil A, Obeso J R, Delibes M (2007) Long-term trends in food habits of a relict brown bear population in northern Spain: the influence of climate and local factors. Environ Conserv 34:36-44 
Saniga M (1998) Diet of the Capercaillie (Tetrao urogallus) in a Central-European mixed spruce-beech-fir and mountain spruce forest. Folia Zool 47:115-124

Sedinger J S (1997) Adaptations to and consequences of an herbivorous diet in grouse and waterfowl. Condor 99:314-326

Selås V (2000) Population dynamics of Capercaillie Tetrao urogallus in relation to bilberry Vaccinium myrtillus production in southern Norway. Wildl Biol 6:1-11

Sutherland W J, Green R E (2004) Habitat assessment. In: Bird Ecology and Conservation. A Handbook of Techniques (ed. Sutherland, W J,Newton, I, Green, R E) pp.251-266. Oxford University Press, New York

Smith T, Skulason S (1996) Evolutionary significance of resource polymorphisms in fishes, amphibians, and birds. Annu Rev Ecol Syst 27:111-133

Storch I (1993) Habitat selection by Capercaillie in summer and autumn: Is bilberry important? Oecologia 95:257-265

Storch I (1994) Habitat and survival of Capercaillie Tetrao urogallus nests and broods in the Bavarian Alps. Biol Conserv 70:237-243

Storch I, Bañuelos M J, Fernández-Gil A, Obeso J R, Quevedo M, Rodríguez-Muñoz R (2006) Subspecies Cantabrian Capercaillie Tetrao urogallus cantabricus endangered according to IUCN criteria. J Ornithol 147:653-655

Storch I, Schwarzmüller C, Von den Stemmen D (1991) The diet of Capercaillie in the Alps: A comparison of hens and cocks. Transactions Congress International Union of Game Biologists, Gödöllö, Hungary 20:630-635

Storch I (2007) Grouse: Status Survey and Conservation Action Plan 2006-2010.

IUCN, Gland, Switzerland and Cambridge, UK, and the World Pheasant Association, Fordingbridge, UK

Summers R W, Proctor R, Thorton M, Avey G (2004) Habitat selection and diet of the Capercaillie Tetrao urogallus in Abernethy Forest, Strathspey, Scotland. Bird Study 51:58-68

Tolvanen A (1994) Differences in recovery between a deciduous and an evergreen ericaceous clonal dwarf shrub after simulated aboveground herbivory and belowground damage. Can J Bot 72:853-859

van Gils J A, Gyimesi A, van Lith B (2007) Avian herbivory: an experiment, a field test, and an allometric comparison with mammals. Ecology 88:2926-2935

Van Valen L (1965) Morphological variation and width of ecological niche. Am Nat 99:377-390 
Wegge P, Olstad T, Gregersen H, Hjeljord O, Sivkov A V (2005) Capercaillie broods in pristine boreal forest in northwestern Russia: the importance of insects and cover in habitat selection. Can J Zool 83:1547-1555 


\section{TABLES}

TABLE 1. Total trophic niche width $(T N W)$ and average proportion of understory-based diet (UD) for different capercaillie populations. Sources: 1- Picozzi et al. 1996; 2Summers et al. 2004; 3- Saniga 1998; 4- Jacob 1988; 5- Storch et al. 1991.

\begin{tabular}{|c|c|c|c|c|c|}
\hline & $T N W$ & UD overall & $\mathrm{UD}_{\text {spring }}$ & $\mathrm{UD}_{\text {summer }}$ & $\mathrm{UD}_{\text {winter }}$ \\
\hline This study & 2.11 & 0.65 & 0.62 & 0.83 & 0.50 \\
\hline Scotland $1^{1}$ & 1.36 & 0.14 & 0.02 & 0.29 & 0 \\
\hline Scotland $2^{2}$ & 0.73 & 0.21 & 0.14 & 0.47 & 0.08 \\
\hline Slovakia $^{3}$ & 1.50 & 0.43 & 0.44 & 0.78 & 0.08 \\
\hline Jura Mountains $^{4}$ & 1.69 & 0.43 & 0.10 & 0.85 & 0.35 \\
\hline Bavarian Alps ${ }^{5}$ & 1.63 & 0.36 & 0.14 & 0.81 & 0.07 \\
\hline
\end{tabular}


TABLE 2. Total niche width $(T N W)$ and mean proportional similarity index (IS \pm standard error) for this study population. The latter varies between 0 and 1 , where diets departing strongly from the population overall approach 0 whereas diets similar to the population average approach $1 . P_{I S}$ indicates the probability of $I S$ being equal to that of a fully generalized overall diet.

\begin{tabular}{lcccc}
\hline & $\mathrm{n}$ & $T N W$ & $I S$ & $P_{I S}$ \\
\hline Pooled dataset & 122 & 2.11 & $0.47 \pm 0.01$ & $<0.0001$ \\
Winter & 30 & 2.08 & $0.45 \pm 0.02$ & $<0.0001$ \\
Spring & 43 & 2.10 & $0.54 \pm 0.02$ & $<0.0001$ \\
Summer / autumn & 49 & 1.74 & $0.61 \pm 0.02$ & $<0.0001$ \\
\hline
\end{tabular}




\section{FIGURE LEGENDS}

FIG.1. Diet and habitat selectivity indexes for canopy and understory species, calculated from the average use of each resource category, and resource availability. a) Diet selection ratio $W_{i}$. It equals 1 when resources are used according to availability. The dashed line at 1 separates resource used above or below availability. * indicates $W_{i}$ was significant after controlling for multiple comparisons (note that significance of $W_{i}$ is calculated on a seasonal basis). Error bars indicate the standard error of $W_{i}$. The numbers on the $\mathrm{X}$-axis correspond to the mean proportional abundance of the canopy and understory species written below them in the X-axis of Fig 1b. Canopy and understory proportions do not add up to 1 as species with less than $1 \%$ cover were not included in the analysis. In the case of seasonal resources like ferns and grasses, we show the seasonal average. b) Habitat selection ratio Wi. Notation and interpretation as above.

FIG.2. Box plots showing the seasonal distribution of the proportional similarity index $I S$. This is an index of specialization of feeding events that approaches 0 for fully specialized feeding events (monodiet), and 1 for those with a generalist pattern. Boxes indicate the interquartile range of the data and the position of the median; error bars extend to non-outlier data within 1.5 times the interquartile range. 
FIG.1
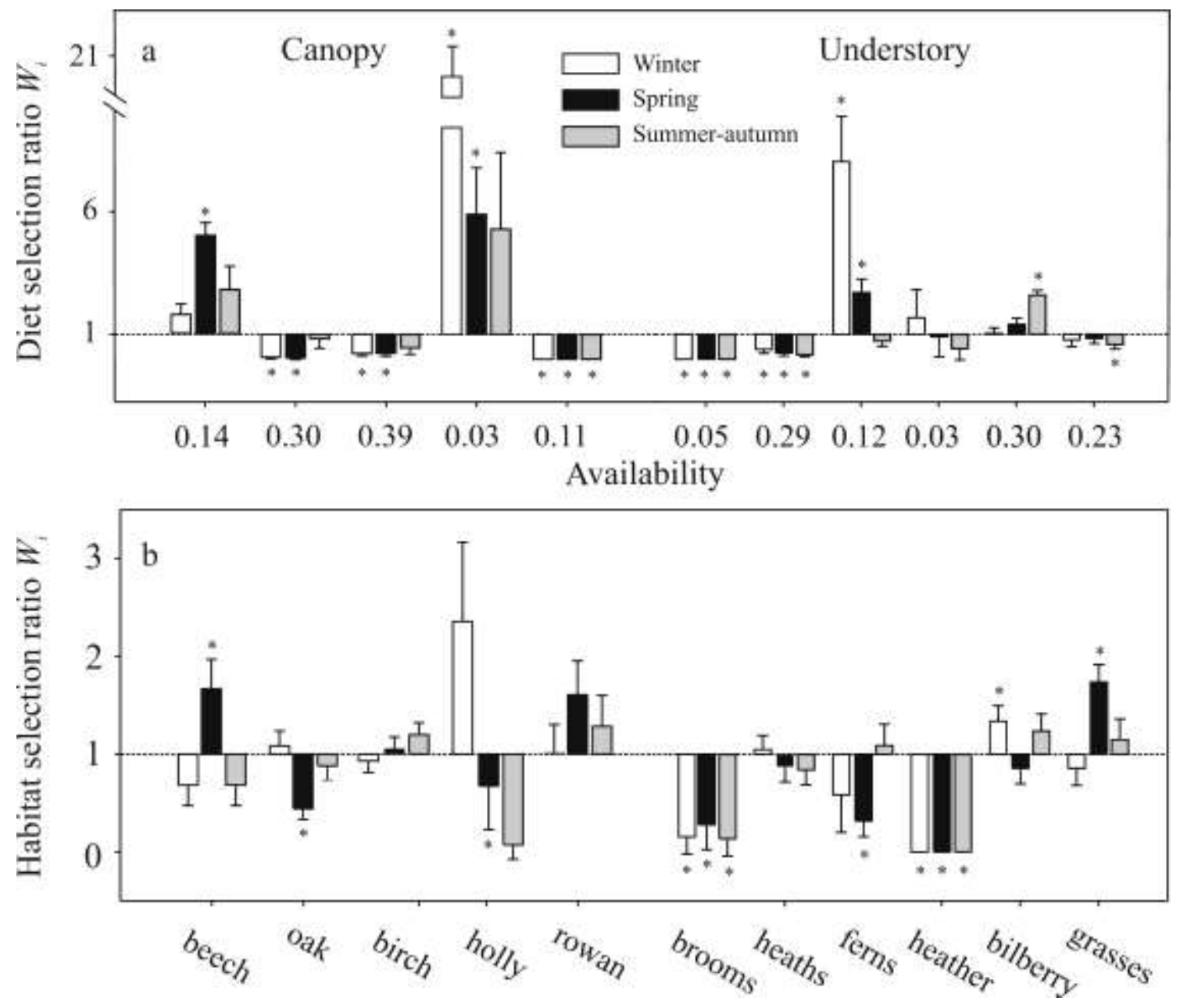
FIG.2

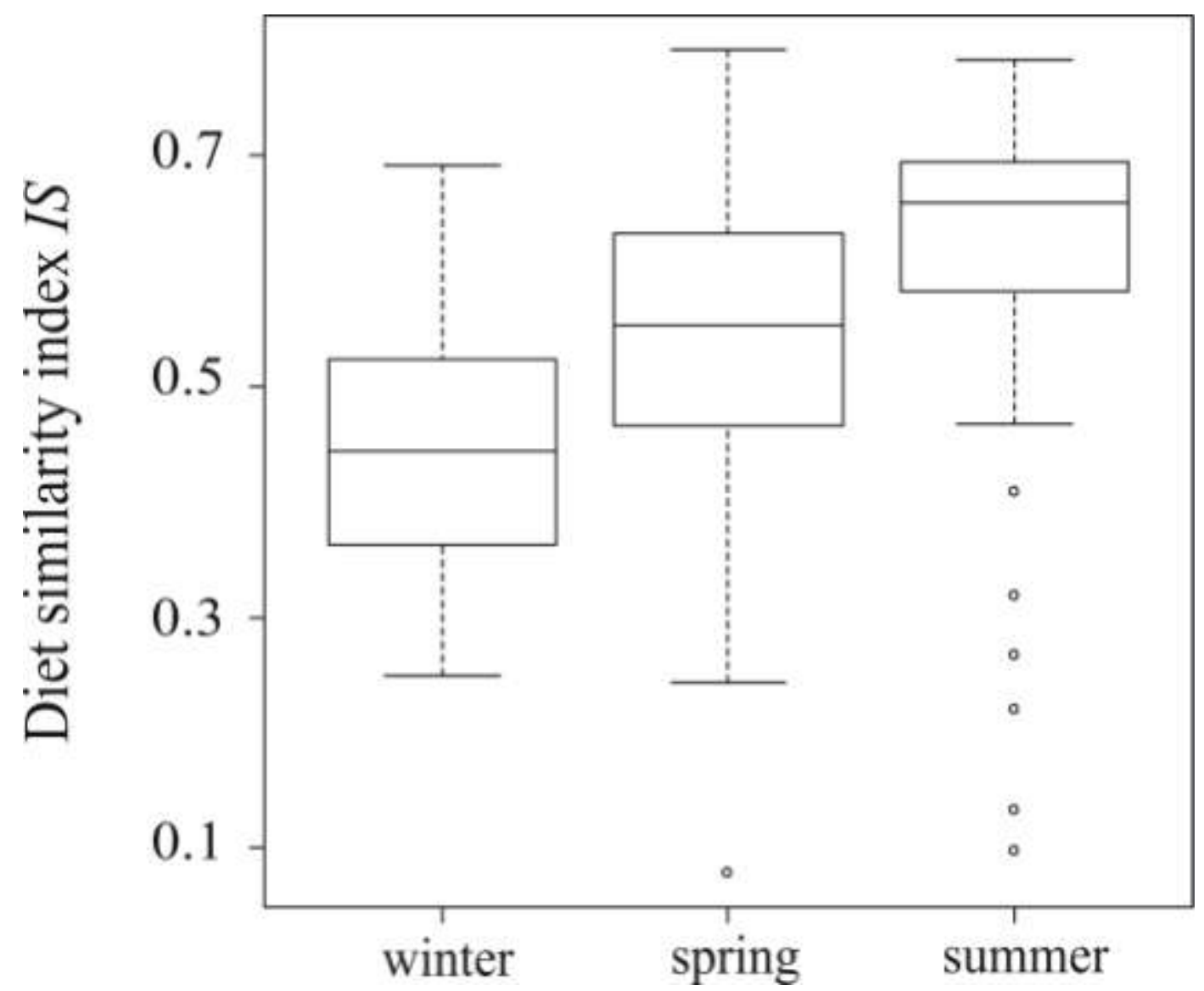


APPENDIX 1. Proportional abundance of resources and proportional use in the diet (mean $\pm 1 \mathrm{SD}$ ) of main canopy and understory species. In the case of seasonal resources like ferns and grasses the average availability value is shown.

\begin{tabular}{|c|c|c|c|c|}
\hline \multirow[t]{2}{*}{ Species } & \multirow[t]{2}{*}{ Availability } & \multicolumn{3}{|c|}{ Proportional diet use } \\
\hline & & Spring & Summer-autumn & Winter \\
\hline Fagus sylvatica & $13.6 \pm 23.6$ & $28.1 \pm 20.8$ & $5.3 \pm 11.4$ & $12.7 \pm 20.2$ \\
\hline Quercus petraea & $29.7 \pm 29.8$ & $0.6 \pm 1.0$ & $3.5 \pm 7.8$ & $1.3 \pm 2.4$ \\
\hline Betula pubescens & $39.3 \pm 26.1$ & $3.9 \pm 5.2$ & $2.5 \pm 8.4$ & $4.8 \pm 11.8$ \\
\hline Ilex aquifolium & $3.2 \pm 6.6$ & $7.8 \pm 21.0$ & $2.4 \pm 13.1$ & $33.0 \pm 37.8$ \\
\hline Sorbus aucuparia & $10.6 \pm 10.4$ & 0 & 0 & 0 \\
\hline Vaccinium myrtillus & $27.8 \pm 16.1$ & $19.1 \pm 16.0$ & $53.6 \pm 27.7$ & $13.3 \pm 14.7$ \\
\hline Erica spp. & $29.2 \pm 19.5$ & $3.7 \pm 5.5$ & $4.0 \pm 6.4$ & $5.4 \pm 5.4$ \\
\hline Calluna vulgaris & $2.7 \pm 11.9$ & $1.2 \pm 2.7$ & $0.9 \pm 1.7$ & $2.1 \pm 3.8$ \\
\hline Cytisus / Genista spp. & $4.5 \pm 8.9$ & 0 & 0 & 0 \\
\hline Ferns & $11.6 \pm 18.6$ & $16.3 \pm 20.8$ & $10.3 \pm 18.1$ & $13.0 \pm 20.4$ \\
\hline Grasses & $22.8 \pm 20.4$ & $4.1 \pm 8.9$ & $3.0 \pm 5.1$ & $2.3 \pm 8.1$ \\
\hline Mosses & - & $6.0 \pm 13.4$ & $5.5 \pm 8.8$ & $4.2 \pm 10.6$ \\
\hline Unidentified & - & $1.1 \pm 1.95$ & $2.6 \pm 3.1$ & $2.9 \pm 5.7$ \\
\hline
\end{tabular}

